\title{
The effect of the calcium antagonist nifedipine on peripheral nerve function in streptozotocin-diabetic rats
}

\author{
S. Robertson, N. E. Cameron and M. A. Cotter \\ Department of Biomedical Sciences, University of Aberdeen, UK
}

\begin{abstract}
Summary. Recent data suggests that reduced nerve blood flow is implicated in the aetiology of experimental diabetic neuropathy, which may be prevented by manipulations that reduce receptor-mediated vasoconstrictor activity. This investigation examines the effects of nifedipine, a voltage-sensitive calcium channel antagonist which has a direct vasodilatory effect on vessels, on nerve conduction, hypoxic resistance and capillary density in streptozotocin-induced diabetic rats. Treated and non-treated non-diabetic and diabetic groups were employed. Diabetes duration was 2 months. Treatment was preventive, groups received a nifedipine dietary supplement $\left(40 \mathrm{mg} \cdot \mathrm{kg}^{-1} \cdot \mathrm{day}^{-1}\right)$ for 2 months from the start of the study. Conduction was measured in sciatic motor branches supplying tibialis anterior and gastrocnemius muscles, and sensory saphenous nerve. Diabetes resulted in a $23-28 \%$ reduction in motor conduction velocity $(p<0.001)$, and a $15 \%$ deficit for sensory saphenous nerve
\end{abstract}

$(p<0.001)$. In the nifedipine-treated diabetic group, motor and sensory conduction deficits were minimal compared with non-treated diabetes $(p<0.001)$. Nifedipine treatment had no significant effect on conduction velocity in nondiabetic rats. In vitro measurement of sciatic nerve hypoxic resistance revealed a $60 \%$ increase in the time taken for compound action potential amplitude to reach half its initial value with diabetes $(p<0.001)$. This was not significantly affected by nifedipine treatment. Experimental diabetes or nifedipine treatment did not significantly alter sciatic nerve endoneurial capillary density. We conclude that nifedipine, a vasodilator which acts directly on vascular smooth muscle, prevents nerve conduction deficits in experimental diabetes.

Key words: Neuropathy, nerve conduction, ischaemia, capillary density, calcium antagonists, streptozotocin, diabetic rat.
Reduced nerve conduction velocity (NCV) and resistance to ischaemic conduction failure (RICF) are early indications of neuropathic dysfunction in both diabetic patients and animals [1]. One view of the underlying aetiology suggests that chronically reduced blood flow, caused by microvascular and rheological changes, leads to endoneurial hypoxia sufficient to impair function [2]. A second hypothesis explains neuropathic changes in terms of a biochemical dysfunction and proposes that increased polyol pathway activity results in deficits in nerve myo-inositol, leading to altered phosphoinositide metabolism and a reduction in $\mathrm{Na}^{+}-\mathrm{K}^{+}$-ATPase activity [3].

The importance of vascular factors in the pathogenesis of diabetic neuropathy has recently been highlighted by studies which show that treatment with the $\alpha_{1}$ blocker prazosin or chronic chemical sympathectomy with guanethidine $[4,5]$ result in improvements in both nerve blood flow, NCV and RICF in streptozotocin-diabetic rats. The rationale for these experiments was that there is increased reactivity to noradrenaline for resistance vessels in ex- perimental diabetes [6], and that sciatic nerve noradrenaline levels are reduced [5,7], perhaps indicating greater release by vasa nervorum sympathetic nerves. Therefore, blockade of sympathetic vasoconstriction could compensate for vasa nervorum insufficiency, reduce endoneurial hypoxia and normalize nerve function. The beneficial effects of vasodilator treatment on diabetic nerve function may not be restricted to drugs that act on the noradrenergic system, as angiotensin converting enzyme inhibition also proved effective [8]. However, different receptormediated agonists exert a co-operative effect in the control of vascular responses, demonstrated, for example, by the use of angiotensin II to reveal postjunctional $\alpha_{2}$-mediated contractions [9]. Thus, it is not clear whether vasodilators which exert relatively uncomplicated effects on membrane ion channels in vascular smooth muscle, such as $\mathrm{Ca}^{2+}$ antagonists, could give effective protection against diabetic vascular complications.

The aim of the present study was to examine the efficacy of nifedipine, which blocks voltage-dependent $\mathrm{Ca}^{2+}$ 
Table 1. Plasma glucose levels and body weights of study animals

\begin{tabular}{lrll}
\hline Group & $n$ & $\begin{array}{l}\text { Plasma glucose } \\
\left(\mathrm{mmol} \cdot 1^{-1}\right)\end{array}$ & $\begin{array}{l}\text { Body weight } \\
(\mathrm{g})\end{array}$ \\
\hline Non-diabetic & & & \\
Onset & 22 & $5.2 \pm 0.7$ & $482 \pm 16$ \\
2-month nifedipine-treated & 5 & $7.8 \pm 0.2$ & $599 \pm 11^{\mathrm{a}}$ \\
Diabetic & & & \\
2 month & 16 & $40.6 \pm 2.4^{\mathrm{a}}$ & $334 \pm 6^{\mathrm{a}}$ \\
2-month nifedipine-treated & 14 & $34.1 \pm 1.4^{\mathrm{a}}$ & $320 \pm 8^{\mathrm{a}}$ \\
Data are means \pm SEM & & & \\
\hline
\end{tabular}

${ }^{\mathrm{a}} p<0.001$ vs non-diabetic onset control group

channels and is relatively specific for vascular smooth muscle [10], in preventing NCV deficits and the development of hypoxic resistance in streptozotocin-diabetic rats. Chronic treatment with both prazosin and an angiotensin converting enzyme inhibitor resulted in endoneurial capillary growth, which correlated with improved nerve function $[4,8]$. A secondary aim of the study was to examine whether nifedipine also caused vasa nervorum angiogenesis.

\section{Materials and methods}

All experiments were carried out on mature male Sprague-Dawley rats (Aberdeen University colony), 19 weeks old and weighing $493 \pm 16 \mathrm{~g}$ at the start of the study. The animals were randomly allocated to four experimental groups. One group of non-treated nondiabetic rats acted as onset controls and were studied at 19 weeks. Another group of non-diabetic rats were given nifedipine (Sigma, Poole, Dorset, UK) in their diet at a concentration of approximately $40 \mathrm{mg} \cdot \mathrm{kg}^{-1} \cdot \mathrm{day}^{-1}$. Diabetes was induced in all other animals by a single injection of streptozotocin $\left(45 \mathrm{mg} \cdot \mathrm{kg}^{-1}\right.$ in $20 \mathrm{mmol} \cdot \mathrm{l}^{-1}$ sodium citrate buffer, $\mathrm{pH} 4.5$, i. p.). Diabetes was verified $24 \mathrm{~h}$ later by estimating hyperglycaemia and glycosuria (Visidex II and Diastix; Ames, Slough, Bucks, UK). Final plasma glucose levels were determined using a standard test kit (GOD-Period method; Boehringer Mannheim, Mannheim, FRG) on samples taken on the day of the experiments. Diabetic animals were divided into two groups. One group remained untreated for 2 months. The other preventivetreated group was fed a diet of normal rat chow to which nifedipine was added (Sigma; approximate dose $40 \mathrm{mg} \cdot \mathrm{kg}^{-1} \cdot \mathrm{day}^{-1}$, for the 2-month period). The dose of nifedipine used, and the method of treatment, is similar to that employed in chronic studies in nondiabetic rats [11], and was chosen to produce a near-maximal ( $>85 \%$ ) blockade of voltage-sensitive $\mathrm{Ca}^{2+}$-channels in arteries of diabetic rats [12].

In final experiments, anaesthesia was initially induced with $5 \%$ halothane in air and maintained by i.p. urethane $\left(1-1.5 \mathrm{~g} \cdot \mathrm{kg}^{-1}\right)$. Animal core temperature was monitored throughout by a rectal temperature probe and maintained at $37-38^{\circ} \mathrm{C}$ by an electrically heated blanket.

Nerve conduction measurements were made in vivo as described previously [13]. For the sciatic motor branches innervating the tibialis anterior (peroneal division) and gastrocnemius (tibial division) muscles, bipolar stimulating electrodes were placed around the sciatic nerve at the notch and knee. A bipolar electrode placed in the relevant muscle recorded electromyograms. Sensory NCV was measured on the saphenous nerve between groin and ankle. NCV was calculated as the interelectrode distance divided by the latency difference between first inflections of potentials evoked at the stimulation sites. Nerve temperatures were monitored with a thermistor probe and regulated between 36.5 and $37.5^{\circ} \mathrm{C}$ by radiant heat.
The in vitro measurement of sciatic nerve resistance to hypoxia (RICF) has previously been described [14]. Briefly, the contralateral sciatic trunk was mounted on bipolar stimulating (proximal) recording (distal) electrodes and left to equilibrate in a chamber filled with Krebs Ringer solution $\left(144.0 \mathrm{Na}^{+}, 5.0 \mathrm{~K}^{+}, 2.5 \mathrm{Ca}^{+}, 1.1 \mathrm{Mg}^{+}\right.$, $25.0 \mathrm{HCO}_{3}{ }^{-}, 1.1 \mathrm{PO}_{4}{ }^{3-}, 1.1 \mathrm{SO}_{4}{ }^{2-}$, in $\mathrm{mmol} \cdot \mathrm{I}^{-1}$, at $35^{\circ} \mathrm{C}$ ) gassed with $95 \% \mathrm{O}_{2}: \mathrm{CO}_{2}$ for approximately $30 \mathrm{~min}$. Glucose concentration was $5.5 \mathrm{mmol} \cdot 1^{-1}$ for nerves of non-diabetic animals, and $40 \mathrm{mmol} \cdot 1^{-1}$ for nerves of diabetic animals. Previous experiments have shown that glucose concentrations over this range have no significant differential effects on RICF for control or diabetic nerves (Cameron, N. E., Cotter, M. A., Cox, D. unpublished observations). The chamber was then refilled with mineral oil which had been pregassed with $100 \% \mathrm{~N}_{2}$ for $1 \mathrm{~h}$, and $\mathrm{N}_{2}$ bubbling was continued. Compound action potentials were evoked by just supramaximal electrical stimulation $(1 \mathrm{~Hz}, 0.05 \mathrm{~ms}$ pulse width, $10 \mathrm{~mA})$ and their amplitude was monitored at 2 -min intervals until it was less than $10 \%$ of the initial value.

At the end of the experiments a length of sciatic nerve between the notch and knee was removed $(2.5 \mathrm{~cm})$, cleared of surrounding tissues and divided into approximately $0.5 \mathrm{~cm}$ pieces. These were then mounted on cork discs using skeletal muscle as support tissue, and frozen in isopentane which had been pre-chilled in liquid nitrogen. Three $10 \mu \mathrm{m}$ thick transverse sections, each $90 \mu \mathrm{m}$ apart, were cut on a cryostat at $-20^{\circ} \mathrm{C}$ and capillary endothelium was stained for alkaline phosphatase using the method of Ziada et al. [15]. Capillaries in all nerve fascicles were counted with the assistance of a projection microscope. Fascicle areas were traced and areas measured using a digitizing pad linked to a microcomputer.

\section{Statistical analysis}

Results are expressed as mean \pm SEM. Data were subjected to oneway analysis of variance. Where statistical significance was attained $(p<0.05)$, Student's $t$-tests were performed between groups to assign probability levels and the Bonferroni correction for multiple comparisons was applied using a commercially available statistical package (Instat; GraphPad, San Diego, Calif., USA).

\section{Results}

All diabetic and treated diabetic animals showed persistent hyperphagia, polydipsia and polyuria. Plasma glucose levels and body weights are summarised in Table 1. Plasma glucose levels were elevated approximately five-fold by diabetes, and were unaffected by nifedipine treatment. Diabetic animals lost weight, irrespective of treatment. Body weights were reduced $31 \%$ below onset values at 2 months in diabetic control animals. A similar reduction was observed in the preventive nifedipine-treated diabetic group. Nifedipine-treated non-diabetic animals increased their weight by $24 \%$, in line with the growth rate for non-treated non-diabetic rats of comparable age [13].

$\mathrm{NCV}$ data for tibialis anterior, gastrocnemius and saphenous nerves are illustrated in Figure 1. Diabetes resulted in an average $25 \%$ reduction $(p<0.001)$ in motor nerve conduction compared with onset controls. Conduction deficits were completely prevented by nifedipine treatment. Sensory saphenous NCV was $15 \%(p<0.001)$ reduced by diabetes. Nifedipine treatment prevented this reduction, the resulting value was not significantly different from that of non-diabetic controls. There were no significant differences between non-diabetic control and non-diabetic nifedipine-treated rats for any of the NCV 


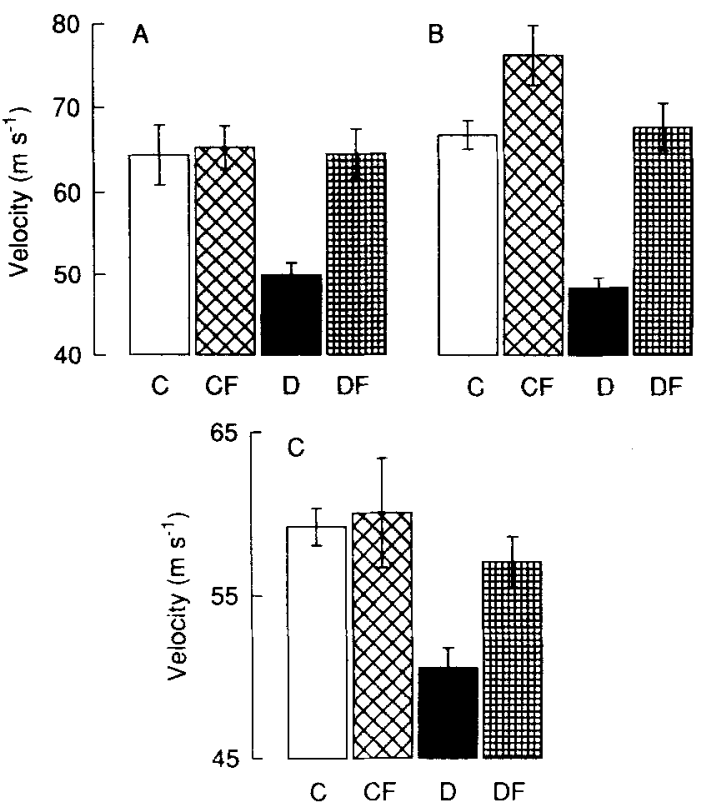

Fig. 1. Conduction velocity in sciatic motor nerves supplying $\mathbf{A}$, gastrocnemius; $\mathbf{B}$, tibialis anterior muscles; and $\mathbf{C}$, sensory saphenous nerve. Bars show means \pm SEM. $\mathrm{C}=$ controls, $n=22$; $\mathrm{CF}=$ nifedipine-treated controls, $n=5 ; \mathrm{D}=$ diabetic controls, $n=16 ; \mathrm{DF}$ $=$ nifedipine-treated diabetic group, $n=14$. Statistical analysis; for all three nerve conduction velocity measurements, $\mathrm{D}$ vs $\mathrm{C}, p<0.001$; DF vs D, $p<0.001$; DF vs C, NS; CF vs C, NS

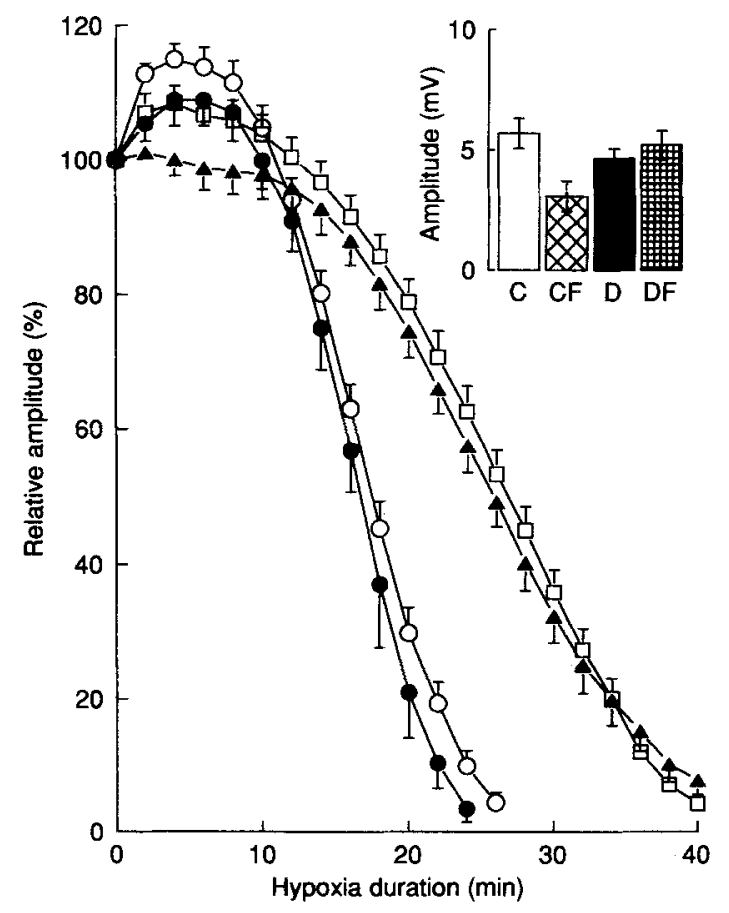

Fig. 2. Percentage change in sciatic nerve compound action potential amplitude with duration of hypoxia in vitro. Symbols and error bars show group means \pm SEM. Controls $(O), n=22$; nifedipinetreated controls $(\bullet), n=5$; diabetic controls $(\square), n=16$; nifedipine-treated diabetic group ( $\mathbf{\Delta}), n=14$. The inset histogram shows initial sciatic nerve compound action potential amplitudes before the period of hypoxia for controls (C), nifedipine-treated controls (CF), diabetic controls (D), nifedipine-treated diabetic group (DF). There were no statistically significant between-group differences in initial amplitude
Table 2. Times for $50 \%\left(\mathrm{~T}_{50}\right)$ and $80 \%\left(\mathrm{~T}_{80}\right)$ reductions in sciatic nerve compound action potential amplitude with hypoxia, and sciatic endoneurial capillarization in non-diabetic and diabetic rats

\begin{tabular}{|c|c|c|c|c|}
\hline \multirow[t]{2}{*}{ Group } & \multirow[t]{2}{*}{$n$} & \multicolumn{2}{|c|}{ Hypoxic resistance } & \multirow{2}{*}{$\begin{array}{l}\text { Capillary } \\
\text { density } \\
\left(\mathrm{mm}^{-2}\right)\end{array}$} \\
\hline & & $\begin{array}{l}\mathrm{T}_{50} \\
(\mathrm{~min})\end{array}$ & $\begin{array}{l}\mathrm{T}_{80} \\
(\min )\end{array}$ & \\
\hline \multicolumn{5}{|l|}{$\overline{\text { Non-diabetic }}$} \\
\hline $\begin{array}{l}\text { Onset control } \\
2 \text {-month nife- } \\
\text { dipine-treated }\end{array}$ & 22 & $16.75 \pm 0.69$ & $\begin{array}{l}21.92 \pm 0.65 \\
20.05 \pm 0.90\end{array}$ & $61.42 \pm 3.01$ \\
\hline \multicolumn{5}{|l|}{ Diabetic } \\
\hline $\begin{array}{l}2 \text { month } \\
2 \text {-month nife- } \\
\text { dipine-treated }\end{array}$ & 14 & $26.84 \pm 0.79^{\mathrm{a}}$ & $33.87 \pm 0.73^{\mathrm{a}}$ & $61.30 \pm 2.23$ \\
\hline Data are means & $\pm S$ & & & \\
\hline
\end{tabular}

${ }^{a} p<0.001$ vs non-diabetic onset control group

measurements, although for tibialis anterior, there may have been a trend towards increased NCV.

Figure 2 shows data for RICF. There were no significant differences in initial compound action potential amplitudes (CAPAs; inset) for any of the groups (range $3.1-5.7 \mathrm{mV}$ ), the lowest value being found for the nifedipine-treated control group. After an initial increase in CAPA, there was a much more prolonged decline, with increasing duration of hypoxia, in non-treated diabetic nerves than in control nerves. Nifedipine treatment had no obvious effect. The progression of conduction failure was very similar to diabetic controls in the nifedipinetreated diabetic rats. Similarly, the curves for nerves from non-diabetic animals, with or without nifedipine treatment, were in close agreement. These findings were reflected in times for $50 \%\left(\mathrm{~T}_{50}\right)$ and $80 \%\left(\mathrm{~T}_{80}\right)$ conduction failure shown in Table 2. Compared to non-diabetic controls, $T_{50}$ and $T_{80}$ levels were elevated by $60 \%$ and $55 \%$ respectively in diabetic animals. A similar increase was found for the nifedipine-treated diabetic group.

Results for sciatic nerve capillary density measurements are also shown in Table 2. No significant differences were found between any of the groups, suggesting that endoneurial capillary density was unaffected by diabetes or nifedipine treatment.

\section{Discussion}

The results demonstrate that treatment with the $\mathrm{Ca}^{2+}$ channel blocker nifedipine prevents the development of both motor and sensory NCV deficits in streptozotocininduced diabetic rats. The changes in non-treated diabetes are unlikely to result from a cytotoxic action of streptozotocin as they are preventable by insulin treatment [16]. In contrast to a recent study which used the $\alpha_{1}$ receptor antagonist prazosin [4] to improve endoneurial blood flow, the effect of nifedipine on NCV was found in the absence of changes in nerve hypoxic resistance or capillarization.

Nifedipine blocks a voltage-sensitive component of $\mathrm{Ca}^{2+}$ influx into vascular smooth muscle, leading to re- 
duced vascular tone $[17,18]$, which would be expected to increase nerve blood flow [19]. Aortae from diabetic rats show increased dependence on extracellular $\mathrm{Ca}^{2+}$ for contractile responses $[20,21]$. Thus, nifedipine may be a more effective vasodilator for diabetic than for non-diabetic rats. This should counteract the increased vascular reactivity seen in diabetes $[6,22]$, which depends on elevated $\alpha$-sensitivity $[23,24]$ and an enhancement of the activity or number of $\mathrm{Ca}^{2+}$ channels in vascular smooth muscle or both [21]. Further contributions to the increased reactivity are made by hypoinsulinaemia [25], reduced synthesis of prostacyclin by neural vessels [7] which may depend on defects in essential fatty acid metabolism [14], and impaired endothelium-dependent relaxation [24, 26-29]. Other rheological effects of diabetes include increased blood viscosity, platelet aggregation, reduced erythrocyte deformability, and decreased oxygen unloading from haemoglobin $[7,30]$. Together, these render nerve endoneurium hypoxic [2], providing a plausible explanation for the basic disturbance underlying the aetiology of diabetic neuropathy.

Nifedipine treatment did not affect RICF in diabetic nerves, which contrasts with the effects on NCV. This could suggest that the mechanisms underlying NCV and RICF are different, or that RICF is a more sensitive indicator of diabetic effects. Factors contributing to the development of hypoxic resistance are disputed. Some authors suggest that RICF is a result of reduced metabolic demand, reflecting decreased $\mathrm{Na}^{+}-\mathrm{K}^{+}$-ATPase activity [31]. Whilst it is agreed that there is a deficit in $\mathrm{Na}^{+}-\mathrm{K}^{+}$-ATPase activity in nerve homogenates from diabetic rats [4, 32,33 , the physiological significance of this has yet to be established [4]. Others have proposed that the development of hypoxic resistance reflects the capacity of nerve to adapt to endoneurial hypoxia, via greater reliance on anaerobic metabolism, [1].

The vascular hypothesis provides an explanation for differential effects on NCV and RICF. Enhanced anaerobic metabolism in response to endoneurial hypoxia can be viewed as a protective mechanism to increase ATP production and limit nerve dysfunction [1]. Clearly, with non-treated diabetes this mechanism only provides partial protection. However, with nifedipine, an improvement in endoneurial oxygenation would be additive with RICF, allowing normal NCV without completely removing the stimulus for increased reliance on anaerobic metabolism. The relative degree of prevention of RICF by vasodilator treatment could simply depend on the extent of the correction of endoneurial hypoxia. This would reflect the degree of smooth muscle relaxation obtainable for a particular vasodilator, and the dose used in treatment. Thus, in prazosin-treated $\left(5 \mathrm{mg} \cdot \mathrm{kg}^{-1} \cdot \mathrm{day}^{-1}\right)$ diabetic rats, $\mathrm{NCV}$ was completely corrected but the rate of increase in RICF was only halved [4]. For the angiotensin converting enzyme inhibitor lisinopril $\left(20 \mathrm{mg} \cdot \mathrm{kg}^{-1} \cdot \mathrm{day}^{-1}\right)$, both $\mathrm{NCV}$ and RICF were normalized [8]. As the dose of nifedipine used in this study was high, close to the top of the concentration-response curve for vessels from diabetic rats in vitro [12], this suggests that the ability of nifedipine to produce vasodilation sufficient to completely prevent abnormalities in nerve function may be limited. One plausible explanation is that nifedipine does not block $\mathrm{Ca}^{2+}$ release from intracellular stores or flux through ligand-gated channels and, therefore, will only partially reduce vasoconstriction produced by noradrenergic stimulation of the $\alpha$-adrenoceptors which control vasa nervorum perfusion [34].

Endoneurial capillary density did not increase in nifedipine-treated diabetic or non-diabetic groups. For diabetic rats, prazosin treatment, omega- 6 essential fatty acid dietary supplementation, and angiotensin converting enzyme inhibition all resulted in approximately $20 \%$ increases in capillary density $[4,8,14]$. The stimulus for vasodilator-induced angiogenesis is the mechanical effect of increased blood flow on endothelium [14, 15, 35]. It is possible that nifedipine treatment did not produce a sufficient increase in blood flow to stimulate capillary growth, or that $\mathrm{Ca}^{2+}$ channel blockade interfered with angiogenesis, for example, by disrupting $\mathrm{Ca}^{2+}$-dependent proteolysis $[36,37]$. However, this does not rule out other effects on vasa nervorum, including increased vessel patency and size [38]. Regardless of the mechanism, the data demonstrate that neo-capillarization is not necessary to prevent NCV deficits in diabetic rats.

In conclusion, nifedipine prevented NCV deficits in streptozotocin-diabetic rats. Given that other diabetic complications such as cardiomyopathy can also be improved by $\mathrm{Ca}^{2+}$ antagonists [39], they could have a potential preventive therapeutic role. The lack of effect on RICF, even at the high dose of nifedipine employed could, however, suggest that actions on nerve may be more limited in practice than those of some other pharmacologically distinct vasodilators $[4,8]$.

Acknowledgement. This work was supported by a grant from the British Diabetic Association.

\section{References}

1. Low PA, Tuck RR, Takeuchi M (1987) Nerve microenvironment in diabetic neuropathy. In: Dyck PJ, Thomas PK, Asbury AK, Winegrad AI, Porte D (eds) Diabetic neuropathy. Saunders, Philadelphia, pp 266-278

2. Tuck RR, Schmelzer JD, Low PA (1984) Endoneurial blood flow and oxygen tension in the sciatic nerves of rats with experimental diabetic neuropathy. Brain 107: 935-950

3. Greene DA, Lattimer SA (1984) Action of sorbinil in diabetic peripheral nerve. Relationship of polyol (sorbitol) pathway inhibition to a myo-inositol mediated defect in sodium-potassium ATPase activity. Diabetes 33: 712-716

4. Cameron NE, Cotter MA, Ferguson K, Robertson S, Radcliffe MA (1991) Effects of chronic $\alpha$-adrenergic receptor blockade on peripheral nerve conduction, hypoxic resistance, polyols, $\mathrm{Na}-\mathrm{K}$ ATPase activity and vascular supply in streptozotocin-diabetic rats. Diabetes 40: 1652-1658

5. Cameron NE, Cotter MA, Low PA (1991) Nerve blood flow in early and experimental diabetes in rats: relation to conduction deficits. Am J Physiol 261: E1-E8

6. Morff RJ (1990) Microvascular reactivity to norephinephrine at different arteriolar levels and durations of streptozotocin-induced diabetes. Diabetes 39: 354-360

7. Ward KK, Low PA, Schmeltzer JD, Zochodone DW (1989) Prostacyclin and noradrenaline in peripheral nerve of chronic experimental diabetes. Brain 112: 107-208 
8. Cameron NE, Cotter MA, Robertson S (1992) Angiotensin converting enzyme inhibition prevents development of muscle and nerve dysfunction and stimulates angiogenesis in streptozotocindiabetic rats. Diabetologia 35: 12-18

9. Dunn WR, McGrath JC, Wilson VG (1991) Postjunctional $\alpha$ adrenoceptors in the rabbit isolated distal saphenous artery: indirect sensitivity to prazosin of responses to noradrenaline mediated via postjunctional $\alpha_{2}$-adrenoreceptors. $\mathrm{Br} J$ Pharmacol 103: 1484-1492

10. Rang HP, Dale MM (1991) Pharmacology. Churchill Livingstone, Edinburgh

11. Nayler WG, Dillon JS, Sturrock WJ (1988) Calcium antagonists and hypertension. Clin Exp Pharmacol Physiol 15: 93-103

12. Pieper GM, Gross GJ (1990) Augmented vascular relaxation to KT-362 in diabetic rat aorta: comparison to diltiazem. J Cardiovasc Pharmacol 16: 394-400

13. Cameron NE, Cotter MA, Robertson S (1989) The effect of aldose reductase inhibition on the pattern of nerve conduction deficits in diabetic rats. Q J Exp Physiol 74: 917-926

14. Cameron NE, Cotter MA, Robertson S (1991) Effects of essential fatty acid supplementation on peripheral nerve and skeletal muscle function and capillarization in streptozotocin diabetic rats. Diabetes 40: 532-539

15. Ziada AMAR, Hudlicka O, Tyler KR, Wright AJA (1984) The effect of long term vasodilation on capillary growth and performance in rabbit heart and skeletal muscle. Cardiovasc Res 18: 724-732

16. Greene DA, Lattimer SA, Ulbrecht J, Carroll P (1985) Glucoseinduced alterations in nerve metabolism: current perspective on the pathogenesis of diabetic neuropathy and future directions for research and therapy. Diabetes Care 8: 290-299

17. Triggle DJ (1982) Biochemical pharmacology of calcium blockers. In: Flaim SF, Zelis R (eds) Calcium blockers: mechanism of actions and clinical applications. Williams and Wilkins, Baltimore, pp 121-134

18. Flaim SF (1982) Comparative pharmacology of calcium blockers based on studies of vascular smooth muscle. In: Flaim SF, Zelis R (eds) Calcium blockers: mechanism of actions and clinical applications. Williams and Wilkins, Baltimore, pp155-178

19. Flaim SF, Kanda K (1982) Comparative pharmacology of calcium channel blockers based on studies of cardiac output distribution. In: Flaim SF, Zelis R (eds) Calcium blockers: mechanism of actions and clinical applications. Williams and Wilkins, Baltimore, pp 179-192

20. White RP, Carrier GO (1988) Enhanced vascular $\alpha$-adrenergic neuroeffector system in diabetes: importance of calcium. Am J Physiol 255: H1036-H1042

21. White RP, Carrier GO (1990) Vascular contraction induced by activation of membrane calcium ion channels is enhanced in streptozotocin-diabetes. J Pharmacol Exp Ther 253: 1057-1062

22. Macleod KM, McNeill JH (1984) The influence of chronic experimental diabetes on contractile responses of rat isolated blood vessels. Can J Physiol Pharmacol 63: 52-57

23. Scarborough NL, Carrier GO (1983) Increased alpha-2 adrenoceptor mediated vascular contraction in diabetic rats. J Autonom Pharmacol 3: 177-183

24. Harris KH, Macleod KM (1988) Influence of the endothelium on contractile responses of arteries from diabetic rats. Eur J Pharmacol 153: 55-64
25. Yagi S, Takata S, Kiyokawa H et al. (1988) Effects of insulin on vasoconstrictive responses to norepinephrine and angiotensin II in the rabbit femoral artery and vein. Diabetes 37: 1064-1067

26. Durante W, Sen AK, Sunhara FA (1988) Impairment of endothelium-dependent relaxation in aortae from spontaneously diabetic rats. Br J Pharmacol 94: 463-468

27. Pieper GM, Gross GJ (1988) Oxygen free radicals abolish endothelium-dependent relaxation in diabetic rat aorta. Am J Physiol 255: H825-H833

28. Kappagoda T, Jayakody L, Rajotte R, Thomson ABR, Senaratne PJ (1989) Endothelium-dependent relaxation to acetylcholine in the aorta of streptozotocin induced diabetic-rat. Clin Invest Med 12:187-193

29. Cameron NE, Cotter MA (1992) Modulation of endothelium dependent relaxation by polyol pathway activity in aorta from chronic streptozotocin-diabetic rats. Eur J Clin Invest 22: A53 (Abstract)

30. Barnes AJ, Locke P, Scudder PR, Dormandy TL, Dormandy JA (1977) Is hyperviscosity a treatable component of diabetic microcirculatory disease? Lancet II: 789-791

31. Lattimer SA, Sima AAF, Greene DA (1989) In vitro correction of impaired $\mathrm{Na}^{+}-\mathrm{K}^{+}$-ATPase in diabetic nerve by protein kinase C agonists. Am J Physiol 256: E264-E269

32. Greene DA, Lattimer SA (1983) Impaired rat sciatic nerve sodium-potassium adenosine triphosphate in acute streptozotocin diabetes and its correction by dietary myo-inositol supplementation. J Clin Invest 72: 1058-1063

33. Lambourne JE, Brown AM, Calcutt N, Tomlinson DR, Willars GB (1988) Adenosine triphosphatase in nerves and ganglia of rats with streptozotocin-induced diabetes or galactosaemia: effects of aldose reductase inhibition. Diabetologia 31: 379-384

34. Kihara M, Low PA (1990) Regulation of rat nerve blood flow: role of epineurial $\alpha$-receptors. J Physiol 422: 145-152

35. Hudlicka O, Tyler KR (1986) Angiogenesis: the growth of the vascular system. Academic Press, New York

36. Berridge MY (1975) The interaction of cyclic neucleotides and calcium in the control of cellular activity. Adv Cyclic Neucleotide Res 6: 1-98

37. D'Amore PA, Shepro D (1977) Stimulation of growth and calcium influx in cultured bovine aortic cells by platelets and vasoactive substances. J Cell Physiol 92: 177-184

38. Zochodne DW, Huang Z, Ward K, Low PA (1990) Guanethidine adrenergic sympathectomy augments endoneurial perfusion and lowers endoneurial microvascular resistance. Brain Res 519: $112-117$

39. Afzal N, Ganguly PK, Dhalla KS, Pierce GN, Singal PK, Dhalla NS (1988) Beneficial effects of verapamil in diabetic cardiomyopathy. Diabetes 37: 936-942

Received: 1 June 1992

and in revised form: 28 July 1992

Dr. N.E. Cameron

Department of Biomedical Sciences

University of Aberdeen

Marischal College

Aberdeen AB9 1AS, Scotland

UK 